\title{
STUDI TENTANG TINGKAT KONDISI FISIK PEMAIN HOCKEY FAKULTAS ILMU KEOLAHRAGAAN UNIVERSITAS NEGERI PADANG
}

\author{
Atradinal $^{1}$, Erick Martina Dharma ${ }^{2}$ \\ Universitas Negeri Padang \\ atr_pykh@yahoo.co.id
}

\begin{abstract}
Abstrack
The problem in this study began with a decline in the achievements achieved by hockey players at the Faculty of Sport Sciences, Padang State University. This article was written to describe the level of physical condition of hockey players at the Faculty of Sport Sciences, Padang State University. As a research population, there were 20 hockey players from the Faculty of Sports Sciences, Padang State University. Sampling using techniques Total sampling amounted to 20 players. Speed data retrieval technique is carried out with a 50 meter run test, endurance with bleep test and agility with an illionis agility test. Data analysis using descriptive statistics. The results of the analysis state that the average speed is 7.43 , the average durability of the 13-19 year age group is 38.07 and the age group 20-29 years is 38.81 , the average agility is 18.48 and the average the physical condition of hockey players from the Faculty of Sport Sciences, Padang State University, amounting to 50.00 can be categorized as being moderate.
\end{abstract}

Keywords: Speed, Durability, Agility, Physical condition, Hockey player

\begin{abstract}
Abstrak
Masalah dalam penelitian ini berawal dari penurunan prestasi yang dicapai pemain hockey Fakultas IImu Keolahragaan Universitas Negeri Padang. Artikel ini ditulis untuk mendeskripsikan tingkat kondisi fisik pemain hockey Fakultas Ilmu Keolahragaan Universitas Negeri Padang. Sebagai populasi penelitian adalah seluruh pemain hockey Fakultas IImu Keolahragaan Universitas Negeri Padang berjumlah 20 orang. Pengambilan sampel menggunakan teknik Total sampling berjumlah 20 orang pemain. Teknik pengambilan data kecepatan dilakukan dengan test lari 50 meter, daya tahan dengan bleep test dan kelincahan dengan illionis agility test. Analisis data menggunakan statistik
\end{abstract}


deskriptif. Hasil analisis menyatakan bahwa rata-rata kecepatan sebesar 7,43, rata-rata daya tahan kelompok umur 13-19 tahun sebesar 38,07 dan kelompok umur 20-29 tahun 38,81, rata-rata kelincahan 18,48 dan rata-rata kondisi fisik pemain hockeyFakultas IImu Keolahragaan Universitas Negeri Padang sebesar 50,00 dapat dikategorikan sedang.

Kata kunci : Kecepatan, Daya tahan, Kelincahan, Kondisi fisik, Pemain hockey.

\section{Pendahuluan}

Hoceky merupakan suatu cabang olahraga yang telah di pertandingkan secara nasional sejak Desember 1950 dalam pekan olahraga mahasiswa di Yogyakarta, namun kebanyakan dari masyarakat belum mengetahui secara pasti tentang olahraga hockey. Hal ini dikarenakan minat masyarakat yang masih kurang ditambah lagi dengan peralatan permainan ini tergolong mahal dan sulit didapat karna kebanyakan peralatan di inport dari luar negeri. Hal ini menyebabkan olahraga ini hanya di dapati dikota - kota besar, ini merupakan kekurangan yang dimiliki club -club hockey di Indonesia.

Permainan ini dimainkan dengan alat berupa tongkat bengkok (stick) untuk memainkan bola dan memindahkan bola dari satu tempat ke tempat yang lain, serta menguasi bola agar tidak direbut pemain lain. Sama halnya dengan sepak bola, tujuan dari permainan ini adalah menciptakan angka sebanyak-banyaknya untuk meraih kemenangan. Menurut Sutanto (2016: 100) "Tujuan permainan ini, setiap tim berlomba-lomba memasukan bola ke gawang lawan masing-masing sebanyak mungkin". Namun gool dapat disahkan dalam permainan hockey tidak seperti halnya sepak bola yang dapat mencetak gool dari jarak jauh, dalam permainan hockeygool disahkan apabila bola dimainkan di dalam circel oleh penyerang dan tidak keluar dari circel sebelum melintasi garis gawang.

Hockey Fakultas IImu Keolahragaan Universitas Negeri Padang merupakan salah satu wadah pembinaan hockey yang ada di Sumatera Barat. Dengan adanya wadah pembinaan ini diharapkan bisa melahirkan pemain-pemain muda yang berkualitas sehingga nantinya mampu membawa nama baik Universitas Negeri Padang maupun Sumatera Barat di tingkat nasional. Dalam mencapai sebuah prestasi yang diinginkan, selama pembinaan tentu tidak terlepas dari 
latihan-latihan yang dilakukan secara terarah dan terpadu yang dilakukan secara terus menerus sehingga pemain dapat memiliki keterampilan dengan baik.

Dalam pembinaan untuk meraih sebuah prestasi bermain hockey tidak terlepas dari pengaruh kondisi fisik, teknik, taktik, dan mental. Persiapan kondisi fisik sangat penting untuk meningkatkan dan memantapkan kualitas teknik. Tanpa persiapan kondisi fisik yang memadai maka akan sulit untuk mencapai prestasi yang tinggi.

Seorang pemain hockey yang handal harus mempunyai kondisi fisik yang baik dan terlatih. MenurutDenise Jenning dalamTaverner (2004: 173) yang merupakan koordinator persiapan fisik di Victoria institute of sport dan merupakan mantan pemain hoki elit, memaparkan mengenai kecepatan, kemampuan aerobik dan anaerobik, serta kelincahan yang mempunyai kontribusi yang signifikan didalam permainan hockey. Irawadi (2014: 103) menyatakan "Kecepatan (speed) disini diartikan sebagai kemampuan seseorang dalam berpindah tempat dari satu titik ke titik yang lainnya dalam waktu yang sesingkatsingkatnya". Setiap pemainharusmampu bersaing dengan kecepatan pemain lawan ketika dilapangan.

Sedangan daya tahan sendiri terbagi menjadi dua yaitu daya tahan aerobic dan daya tahan anaerobik. Daya tahan aerobic adalah kemampuan seseorang untuk melakukan kerja dalam suasana aerobik, dan daya tahan anaerobic adalah kemampuan seseorang untuk melakukan kerja dalam suasana anaerobik. Daya tahan aerobik yang kuat sangat penting, terutama untuk pemain gelandang. Akan tetapi, semua pemain lapangan memerlukan dasar aerobik yang kuat untuk mengembangkan kemampuan lainnya. Kemampuan aerobik yang kuat memungkinkan pemain untuk berlari sepanjang permainan serta memberikan kesempatan terbaik untuk pemulihan. Sedangakan daya tahan anaerobik yang baik memungkinkan pemain untuk mengulang lari sprint sepanjang pertandingan. Pemain dalam posisi manapun perlu memiliki kebugaran anaerobik. Kemampuan lari sprint menuju posisi serangan atau mengejar ke posisi pertahanan dengan kecepatan dan tanpa kelelahan penting bagi seluruh pemain.

Agus (2012: 71) menyatakan "Kelincahan (agilitas) adalah kemampuan seseorang untuk dapat mengubah arah dengan cepat dan tepat pada waktu bergerak tanpa kehilangan keseimbangan". Kemampuan untuk merubah arah dengan cepat sangat penting untuk pemain depan karna mereka mencoba untuk 
mengeliminasi lawan terdekat mereka. Tentu saja, kelincahan juga penting bagi para bek yang perlu bereaksi terhadap gerakan ini.

Kondisi fisik yang baik dapat meningkatkan dan memantapkan kualitas teknik. Hal ini dapat dipahami karena gerakan-gerakan dalam olahraga hockey sangat tergantung pada penguasaan teknik-teknik dasar yang baik sehingga mampu menunjang kelancaran permainan sesungguhnya nanti. Oleh karna itu kondisi yang prima menjadi syarat mutlak untuk mendapatkan prestasi yang tinggi

Dewasa ini dapat di lihat bahwa prestasi yang dimiliki oleh para pemain hockeyFakultas IImu Keolahragaan Universitas Negeri Padang terus mengalami penurunan. Hal ini mungkin disebabkan oleh banyak hal seperti pembinaan kondisi fisik pemain, penerapan taktik dan teknik dalam pertandingan,mental bertanding, sarana dan prasarana pendukung dalam latihan dan juga partisipasi pemerintah dalam pembinaan hockey. Kemampuan kondisi fisik pemain yang masih rendah menjadi salah satu masalah yang paling menonjol, terbukti pada kejuaran nasional dan pra- PON yang diadakan di Jakarta pada 15-22November 2015, FHI Sumatera Barat yang diwakili oleh pemainhockeyFakultas IImu Keolahragaan Universitas Negeri Padang hanya mampu meraih peringkat 11 dari 11 Provinsi yang mengikuti. Terlihat bahwa kekalahan-kekalahan yang diperoleh dikarena lemahnya kondisi fisik yang dimiliki para pemain.

Peneliti melihat banyak kendala yang di hadapi pemain ketika dilapangan seperti pada unsur kecepatan, daya tahan dan juga kelincahan. Pada banyak kesempatan pemain terlihattidak mampu mengejar dan menerima operan bola daerah. Bola selalu mampu diamankan oleh pemain lawan, sehinggasangat sulit untuk menyelesaikan peluang yang didapat didalam suatu pertandingan.

Begitu pula pada daya tahan, para pemainhanya memiliki kondisi fisik yang prima di babak pertama dan di babak kedua cendrung mengalami penurunan performa, hal ini tentu disebabkan oleh rendahnya daya tahan aerobik para pemain.Begitu pula dengan daya tahan anaerobik, pada saat transisi antara menyerang ke bertahan yang masih tergolong lambat. Hal ini disebabkan karena para pemain tidak dapat mengatasi kelelahan setelah melakuakan penyerangan. Sehingga saat serangan gagal dan bola berhasil di kuasai oleh lawan, para pemain tidak siap untuk melakukan pertahanan. Lemahnya daya tahan aerobik dan anaerobik yang di miliki para pemain menyebabkan para pemain tidak bisa bermain dengan 
maksimal dalam melaksanakan tugasnya di masing - masing lineing di dalam lapangan.

Sedangakan pada unsur kelincahan, lemahnya kemampuan merubah arah yang dimiliki para pemain hockeyFakultas IlmuKeolahragaanUniversitasNegeri Padang sangat jelas terlihat saat lawan moncoba melepaskan diri dari penjagaan sehingga lawan dengan mudah mendapatkan posisi yang nyaman dalam menerima bola. Hal ini disebabkan oleh kelincahan yang dimiliki pemain masih tergolong rendah. Kekurangan - kekurangan yang dimiliki para pemain hockey Fakultas IImu Keolahragaan Universitas Negeri Padang ini tentu berdampak pada hasil pertandingan.

Peneliti menduga yang menyebabkan masih kurangnya kemampuan kecepatan, daya tahan dan kelincahan yang dimiliki pemain hockey Fakultas IImu Keolahragaan Universitas Negeri Padang ialah para memain tidak mengikuti intruksi pelatih dengan benar pada saat latihan kecepatan. Hal ini terlihat pada sesi latihan kecepatan, upaya yang dilakukan oleh pemain saat latihan tidak 100 \% sehingga pemain tidak mampu mencapai kecepatan maksimalnya. Lalu latihan-latihan yang ada tidak dilakukan secara sistematis. Maksudnya banyak pemain hanya melakukan latihan daya tahan menjelang keberangkatan, sedangkan daya tahan yang baik tidak bisa didapat dalam waktu singkat. Selanjutnya pemain tidak mampu mengikuti arahan pelatih saat latihan khususnya pada unsure kelincahan sehingga tujuan latihanitu sediri tidak tercapai. Oleh karna itu peneliti merasa perlu untuk melakukan penelitian untuk menggambarkan bagaimana kecepatan, daya tahan dan kelincahan yang dimiliki oleh pemain hockey Fakultas Ilmu Keolahragaan Universitas Negeri Padang.

\section{Metode}

Menurut Arikunto (2002: 78) "Penelitian deskriptif adalah penelitian yang tidakbermaksud untuk menguji hipotesis tertentu, tapi hanya menggambarkan apaadanya tentang suatu variabel, gejala atau keadaan". Dengan demikian penelitian ini hanya akan menggungkapkan atau pun menggambarkan suatu gejala semata, yang bertujuan untuk mengetahui tingkat kondisifisik pemain hockeyFakultas IImu Keolahragaan Universitas Negeri Padang.Penelitian ini dilaksanakan dilapangan dan GOR PPSP Sekolah Pembangunan Laboratorium Universitas Negeri Padang pada kamis, 12 Oktober 2017. 
Populasi dalam penelitian ini adalah Mahasiswa Fakultas Ilmu Keolahragaan yang tedaftar atau megikuti latihan olahraga hockey di Fakultas IImu Keolahragaan Universitas Negeri Padang yaitu sebayak 20 orang putra Sampel penelitian ini berjumlah 20 orang.

\section{Hasil dan Pembahasan}

Berdasarkan data kecepatan yang didapat dari 20 responden penelitian, diperoleh data sebagai berikut, skor tertinggi 6,6, skor terendah 8,7, rata - rata 7,43 dan standar deviasi 0,51, untuk lebih jelas dapat dilihat pada tabel 1 .

\begin{tabular}{|l|l|l|l|}
\hline Katagori & $\mathrm{Xi}$ & $\mathrm{Fi}$ & $\mathrm{Fr}(\%)$ \\
\hline Baik sekali & $<4,6$ & 0 & $0 \%$ \\
\hline Baik & $4,7-5,7$ & 0 & $0 \%$ \\
\hline Sedang & $5,8-6,8$ & 3 & $15 \%$ \\
\hline Kurang & $6,9-7,9$ & 15 & $75 \%$ \\
\hline $\begin{array}{l}\text { Kurang } \\
\text { sekali }\end{array}$ & $>8,0$ & 2 & $10 \%$ \\
\hline Jumlah & & 20 & $100 \%$ \\
\hline
\end{tabular}

Berdasarkan tabel 1, dapat disimpulkan hasil distribusi data dari kemampuan pemain berbeda, tidak ada pemain yang mampu mencapai pada kategori baik sekali dan baik, pada katagori sedang sebanyak 3 orang (15\%), katagori kurang 15 orang (75 \%) dan kurang sekali 2 orang (10\%). Rata - rata tingkat kecepatan sebesar 7,43 dapat dikategorikan kurang.

Lalu berdasarkan data dayatahan yang didapat dari 20 responden penelitian, diperoleh data sebagai berikut, data di pisah menjadi 2 kelompok umur yaitu umur 13 - 19 tahun dan kelompok umur $20-29$ tahun. Untuk kelompok umur 13 - 19 tahun skor tertinggi 44,2, skor terendah 33,9, rata - rata 38,07 dan standar deviasi 3,39, untuk lebih jelas dapat dilihat pada tabel 2.

\begin{tabular}{|c|c|c|c|}
\hline Kategori & $\mathrm{Xi}$ & $\mathrm{Fi}$ & $\mathrm{Fr}(\%)$ \\
\hline Superior & $>55,9$ & 0 & $0 \%$ \\
\hline Excellent & $51,0-55,9$ & 0 & $0 \%$ \\
\hline $\begin{array}{c}\text { Diatas } \\
\text { rata-rata }\end{array}$ & $45,2-50,9$ & 0 & $0 \%$ \\
\hline
\end{tabular}




\begin{tabular}{|c|c|c|c|}
\hline Rata-rata & $40,5-45,1$ & 1 & $16,67 \%$ \\
\hline $\begin{array}{c}\text { Dibawah } \\
\text { rata-rata }\end{array}$ & $35,0-39,9$ & 4 & $66,67 \%$ \\
\hline Jelek & $<35,0$ & 1 & $16,67 \%$ \\
\hline \multicolumn{2}{|c|}{ Jumlah } & 6 & $100 \%$ \\
\hline \multicolumn{4}{|l}{} \\
\hline
\end{tabular}

Berdasarkan tabel 2, dapat disimpulkan hasil distribusi data dari $\mathrm{VO}_{2}$ Max para pemain, tidak ada pemain yang mampu mencapai pada kategori superior ,excellent dan diatas rata-rata. Sedangkan pada katagorirata-rata1 orang $(16,67 \%)$, kategori dibawah rata-rata sebanyak 4 orang $(66,67 \%)$, kategori jelek 1 orang $(16,67 \%)$ dan rata - rata $\mathrm{VO}_{2}$ Maxkelompok umur 13-19 tahun sebesar 38.07dapat dikategorikan dibawah rata-rata.Sedangkan untuk kelompok umur 20 - 29 tahun, skor tertinggi 49,6, skor terendah 34,3, rata - rata 38,81 dan standar deviasi 4,17, untuk lebih jelas dapat dilihat pada tabel 3 .

\begin{tabular}{|c|c|c|c|}
\hline Kategori & $\mathrm{Xi}$ & $\mathrm{Fi}$ & $\operatorname{Fr}(\%)$ \\
\hline Superior & $>52,6$ & 0 & $0 \%$ \\
\hline Excellent & $49,3-52,5$ & 1 & $7,14 \%$ \\
\hline $\begin{array}{c}\text { Diatas rata- } \\
\text { rata }\end{array}$ & $43,9-48,7$ & 1 & $7,14 \%$ \\
\hline Rata-rata & $39,9-43,3$ & 3 & $21,43 \%$ \\
\hline $\begin{array}{c}\text { Dibawah rata- } \\
\text { rata }\end{array}$ & $33,0-39,2$ & 9 & $64,29 \%$ \\
\hline Jelek & $<33,0$ & 0 & $0 \%$ \\
\hline \multicolumn{2}{|c|}{ Jumlah } & 14 & $100 \%$ \\
\hline
\end{tabular}

Berdasarkan tabel 3, dapat disimpulkan hasil distribusi data dari $\mathrm{VO}_{2} \mathrm{Max}$, tidak ada pemain yang mampu mencapai pada kategori superior, pada katagori excellent sebanyak 1 orang $(7,14 \%)$, pada katagori diatas rata-rata sebanyak1 orang $(7,14 \%)$, pada katagorirata-rata sebanyak 3 orang $(21,43 \%)$, pada kategori dibawah rata-rata sebanyak 9 (64,29\%) dan tidak ada pemain yang masuk pada kategori jelek. Sedangkan rata - rata $\mathrm{VO}_{2}$ Maxkelompok umur 20-29 sebesar 38,81dapat dikategorikan dibawah rata-rata. 
Lalu berdasarkan data kelincahan yang didapat dari 20 responden penelitian, diperoleh data sebagai berikut, skor tertinggi 16,7 , skor terendah 20,4 , rata rata 18,46 dan standar deviasi 0,97, untuk lebih jelas dapat dilihat pada tabel 4 .

\begin{tabular}{|c|c|c|c|}
\hline Kategori & $\mathrm{Xi}$ & $\mathrm{Fi}$ & $\mathrm{Fr}(\%)$ \\
\hline Sangatbaik & $<15,2$ & 0 & $0 \%$ \\
\hline Baik & $15,2-16,1$ & 0 & $0 \%$ \\
\hline Sedang & $16,2-18,1$ & 6 & $30 \%$ \\
\hline Kurang & $18,2-18,3$ & 2 & $10 \%$ \\
\hline Sangatkurang & $>18,3$ & 12 & $60 \%$ \\
\hline \multicolumn{2}{|c|}{ Jumlah } & 20 & $100 \%$ \\
\hline
\end{tabular}

Berdasarkan tabel 4, dapat disimpulkan hasil distribusi data dari kelincahan, tidak ada pemain yang mampu mencapai pada kategori baik sekalidanbaik, sedangkanpada katagori sedang sebanyak 6 orang (30\%), katagori kurang2 orang (10\%)danpadakatagorisangatkurang12 orang (60\%). Sedangkan rata rata kelincahansebesar 18,46 dapat dikategorikan sangatkurang.

Berdasarkan dari data kondisi fisik, diperoleh data sebagai berikut, skor tertinggi 66,25 , skor terendah 41,77 , dan rata - rata 50,00, untuk lebih jelas dapat dilihat pada tabel 5.

\begin{tabular}{|c|c|c|c|}
\hline Kategori & $\mathrm{Xi}$ & $\mathrm{Fi}$ & $\mathrm{Fr}(\%)$ \\
\hline Baik Sekali & $\geq 61,01$ & 2 & $10 \%$ \\
\hline Baik & $53,67-61,00$ & 4 & $20 \%$ \\
\hline Sedang & $46,33-53,66$ & 6 & $30 \%$ \\
\hline Kurang & $38,99-46,32$ & 8 & $40 \%$ \\
\hline \multicolumn{2}{|c|}{ Jumlah } & 20 & $100 \%$ \\
\hline
\end{tabular}

Berdasarkan tabel 5, dapat disimpulkan hasil distribusi data dari kondisi fisik para pemain yaitu, pemain yang mampu mencapai pada kategori baik sekalisebanyak 2 orang (10\%), kategoribaik 4 orang (20\%), sedangkanpada katagori sedang sebanyak 6 orang (30\%) dan katagori kurang8 orang (40\%). Sedangkan rata rata kondisi fisiksebesar 50,00dapat dikategorikan sedang.

\section{Pembahasan}

Dari hasil test kecepatan dengan menggunakan test lari 50 meter di peroleh tingkat kecepataan pemain termasuk dalam kategori kurang. Hal initerbuktidengantidak adanya pemain yang mampu mencapai pada kategori baik sekali dan baik, pada katagori sedang sebanyak 3 orang (15\%), katagori kurang 15 orang $(75 \%)$ dan kurang sekali 2 orang (10\%).Dari persentase yang ada, 
diketahui bahwa kecepatan yang dimilik oleh pemain masih kurang. Hal ini disebabkan banyak faktor, salah satunya pemain tidak mengikuti instruks ipelatih dengan serius saat latihan khususnya pada unsure kecepatan sehingga latihan menjadi tidak maksimal.

Setiap pemainharusmampu bersaing dengan kecepatan pemain lawan ketika dilapangan. Didalam permainan hockey kecepatan juga menentukan keberhasilan pemain dalam melewati musuh dalam rangka menyelesaikan peluang yang didapat didalam suatu pertandingan. Untuk mencapai semua itu, tentu harus ada latihan dengan upaya 100\% yang dapat meningkatkan kecepatan pemain. Menurut Taverner (2004: 175) berikut ini merupakan contoh latihan yang dapat dilakukan untuk mengembangkan kecepatan pemain :

1. Pemanasan, termasuk latihan sprint dan peregangan dinamis.

2. $4 \times 20$ meter lari sprint dengan upaya $100 \%$ dengan $1-2$ menit istirahat antar setiap set.

3. $3 \times 15$ meter sprint dengan star melayang dengan 1-2 menit istirahat antar sprint.

4. $6 \times 10$ meter sprint dengan posisi awalan yang berbeda dengan 1 menit istirahat antar upaya.

5. jogging pendinginan ditambah peregangan.

Kemudian untuk daya tahan, Hasil testdibagi menjadi 2 kelompok umur yaitu umur 13-19 tahun dan 20-29 tahun. Dari hasil test dayatahan pada kelompok umur 13-19 tahundengan menggunakanbeep test di peroleh kemampuan $\mathrm{VO}_{2} \mathrm{Max}$ pemain termasuk dalam kategori di bawah rata-rata. Hal ini terbukti dengan tidak ada pemain yang mampu mencapai pada kategori superior ,excellent dan diatas rata-rata. Sedangkan pada katagorirata-rata1 orang (16,67\%), kategori dibawah rata-rata sebanyak 4 orang (66,67\%), kategori jelek 1 orang (16,67\%).Sedangkan darihasil test dayatahan pada kelompok umur 20-29 tahun dengan menggunakan beep test di peroleh kemampuan $\mathrm{VO}_{2} \mathrm{Max}$ pemain termasuk dalam kategori dibawah rata-rata.Hal ini terbukti dengan tidak ada pemain yang mampu mencapai pada kategori superior, pada katagori excellent sebanyak 1 orang $(7,14 \%)$, pada katagori diatas rata-rata sebanyak1 orang (7,14\%), pada katagori rata-rata sebanyak 3 orang $(21,43 \%)$, pada kategori dibawah rata-rata sebanyak 9 (64,29\%) dan tidak ada pemain yang masuk pada kategori jelek. Berdasarkan dari kedua data tersebut, diketahui bahwa daya 
tahan yang dimiliki oleh pemain masih rendah. Hal ini disebabkan banyak faktor, salah satunya adalah latihan yang tidak sistematis kususnya pada latihan daya tahan.

Dalam suatu pertandingan pemain dituntut mampu bergerak lebih lama tanpa mengaami kelelahan yang berarti dalam melaksanakan tugasnya . seorang pemain harus selalu bergerak mengiringi kemana arah bola dimainkan dengan tetap memperhatikan pergerakan lawan. Jika seseorang tidak memiliki daya tahan yang baik, maka dia akan kesulitan dalam mengikuti jalannya suatu pertandingan, walaupun pemain tersebut mempunya kemampuan penguasaan permainan yang baik. Walau pun unsur kondisi fisik yang lain bagus tatapi tidak didukung oleh daya tahan yang bagus pula, maka pencapaian prestasi pasti akan terhambat. Untuk mendapatkan daya tahan yang baik harus ada latihan yang bertujuan untuk meningkatkan daya tahan secara sistematis. Menurut Taverner (2004: 175) berikut ini merupakan metode pelatihan yang bisa digunakan untuk mengembangkan basis aerobik :

1. Pelatihan berkelanjutan pada denyut jantung yang konstan dalam kisaran 140 - 160 denyut per menit. anda dapat menentukan zona pelatihan dengan menggunakan rumus 220 dikurangi usia anda (detak jantung maksimal anda) dikalikan dengan $0.60-0.80$. atlet yang lebih berpengalaman dan elit akan dapat memiliki feelyang lebih baik dan zona pelatihan khusus mereka dikarenakan pengalaman dan tahun-tahun pelatihan mereka.

2. Pelatihan Faterlek.

3. Sesi interval berbasis.

Lalu Dari hasil test kelincahan dengan menggunakan metode illionis agility test di peroleh tingkat kelicahan pemain termasuk dalam kategori sangat kurang. Hal ini terbukti dengan tidak ada pemain yang mampu mencapai pada kategori baik sekali dan baik, sedangkan pada katagori sedang sebanyak 6 orang (30\%), katagori kurang2 orang (10\%)dan pada katagori sangat kurang12 orang (60\%). Dari persentase yang ada, diketahui bahwa kelincahan yang dimiliki oleh pemain hockey sangat kurang. Hal ini disebabkan banyak faktor, salah satunya pemain tidak mampu mengikuti arahan pelatih dengan benar saat latihan khususnya pada unsure kelincahan sehingga tujuan latihan itu sediri tidak tercapai. 
Kelincahan (agilitas) adalah kemampuan seseorang untuk dapat mengubah arah dengan cepat dan tepat pada waktu bergerak tanpa kehilangan keseimbangan. Namunlemahnya kemampuan merubah arah yang dimiliki para pemain hockeydapat dimanfaatkan oleh lawan untuk moncoba melepaskan diri dari penjagaan sehingga lawan dengan mudah mendapatkan posisi yang nyaman dalam menerima bola. Hal ini disebabkan oleh kelincahan yang dimiliki pemain masih tergolong rendah. Kemampuan untuk merubah arah dengan cepat sangat penting untuk pemain depan karna mereka mencoba untuk mengeliminasi lawan terdekat mereka. Tentu saja, kelincahan juga penting bagi para bek yang perlu bereaksi terhadap gerakan ini. Untuk itu perlu adanya latihan yang dapat meningkatkan kelincahan pemain, salah satunya yaitu latihan lari zig-zag dan lari bolak balik dengan membawa stick yang dilakukan dengan upaya $100 \%$ agar mendapat hasil yang maksimal.

Kemudian berdasarkan hasil analisis data yang dilakukan menunjukkan tingkat kondisi fisik pemain berbeda, dan hasil analisis ditunjukkan yang terbagi menjadi empat kategori. Kategori baik sekali $10 \%$,kategori baik $20 \%$, kategori sedang 30 $\%$ dan kategori kurang $40 \%$. Jadi dapat disimpulkan bahwa tingkat kecepatan pemain berada di kategori sedang.

Hal ini tentu mempengaruhi terhadap capaian prestasi para pemain. Untuk mendapatkan prestasi yang tinggi tersebut, para pemain harus memiliki kondisi fisik yang perima, namun pada kenyataannya kondisi fisik para pemain masih kurang untuk mencapai prestasi yang tinggi. Oleh karna itu perlu adanya latihanlatihan yang dapat meningkatkan kondisi fisik agar bisa mencapai prestasi yang di inginkan.

\section{Kesimpulan}

Berdasarkan analisis data dan pembahsan pada bab iv, maka dapat ditarik kesimpulan sebagai berikut :

1. Kecepatan dari hasil test lari 50 meter, dapat diambil kesimpulan tingkat kecepatan pemain hockey Fakultas IImu Keolahragaan Universitas Negeri Padang berada pada kategori kurang.

2. Daya tahandari hasil Beep Test, dapat diambil kesimpulan tingkat $\mathrm{VO}_{2} \mathrm{Max}$ pemain hockey Fakultas IImu Keolahragaan Universitas Negeri Padang berada pada kategori dibawah rata-rata. 
3. Kelincahandari hasil Illionis Agility Test, dapat diambil kesimpulan tingkat kelincahan pemain hockey Fakultas IImu Keolahragaan Universitas Negeri Padang berada pada kategori sangat kurang.

4. Kondisi fisik dari deskripsi data, dapat diambil kesimpulan tingkat kondisi fisik pemain hockey Fakultas IImu Keolahragaan Universitas Negeri Padang berada pada kategori sedang.

\section{Saran}

Berdasarkan kesimpulan di atas, maka penulis dapat memberikan saran-saran sebagai berikut :

1. Pelatih hockey Fakultas IImu Keolahragaan Universitas Negeri Padang agar dapat memperhatikan dan lebih meningkatkan lagi latihan yang terprogram secara sistematis terutama latihan - latihan yang berhubungan dengan kondisi fisik seperti, kecepatan, daya tahan dan kelincahan.

2. Kepada pemain hockey Fakultas IImu Keolahragaan Universitas Negeri Padang agar dapat meningkatkan kondisi fisik dengan berlatih yang rajin, melaksanakan latihan dengan serius dan selalu mematuhi istruksi yang diberikan pelatih pada saat latihan.

3. Kepada para peneliti yang akan meneliti tentang kondisi fisik pemain hockey disarakan untuk dapat mengkaji komponen kondisi fisik yang lainnya yang dapat mendukung pencapaian prestasi yang lebih baik.

\section{Daftar Rujukan}

Agus, Apri. 2012. Olahraga Kebugaran Jasmani. Padang : Sukabina Press

Arikunto, Suharmi. 2002. Prosedur Penelitian. Jakarta : Renika Cipta.

Arsil. 2015. Pembinaan Kondisi Fisik. Padang : FIK UNP.

Arsil. 2015. Evaluasi Pendidikan Jasmani Dan Olahraga. Malang : Wineka Media. Bafirman, dan Apri agus. 2010. Pembentukan Kondisi Fisik. Malang : Wineka Media.

Bbcsport. 2005. "Basic Dribble".news.bbc.co.uk/ sport2/ hi/ other sports/ hockey/ 4186898.stm, diakses 31 Oktober 2017.

Bbcsport. 2005. "The Block Tackle".news.bbc.co.uk/ sport2/ hi/ other sports/ hockey/ 4186996.stm, diakses 31 Oktober 2017.

Bbcsport. 2005. "The Jab Tackle".news.bbc.co.uk/ sport2/ hi/ other sports/ hockey/ 4186968.stm, diakses 31 Oktober 2017. 
Fakultas IImu Keolahragaan Universitas Negeri Jakarta. 2015. "Panduan Uji Uji Kompetisi SBMPTN 2015". fik.unj.ac.id/?wp-content/ uploads/2015/ 05/ INSTRUKSI-Ujian-Keterampilan-OLAHRAGA-SBMPTN-2015.pdf, diakses 31 Oktober 2017.

Fieldhockey.isport.com/fieldhockey-guides/how-to-the-ball-in-field-hockey, diakses 30 Oktober 2017.

Fieldhockey.isport.com/fieldhockey-guides/how-to-play-stopper-on-a-penaltycorner, diakses 30 Oktober 2017

Irwadi, Hendri. 2014. Kondisi Fisik dan Pengukurannya. Padang : UNP Press.

Kurniawan, Feri. 2011. Buku Pintar Olahraga. Jakarta : Laskar Aksara

Kurniawan, Feri. 2012. Buku Pintar Pengetahuan Olahraga. Jakarta Timur: Laskar Aksara

Lita. 2017. "6 Teknik Bermain Hoki Yang Benar". Olahragapedia.com/teknikdasar-hoki, diakses 30 Oktober 2017.

Lubis, Johansyah. 2014. Pencak Silat. Jakarta. PT Rajagrafindo Persada

Markwica, Whitney. 2015. “16 Things All Field Hockey Players Understand”. https://www.theodysseyonline.com/16-things-field-field-hockey-playersunderstand, diakses 31 Okteober 2017.

Mawardi. 2009. Permainan Hoki. Malang : Wineka Media.

Muhajir. 2007. Pendidikan Jasmani, Olahraga, dan Kesehatan. Bandung : Ghaliah Indonesia Printing.

Purnama, Ardi. 2014. "Cara Mengukur Kesegaran Jasmani/Kondisi Fisik Pemain Bola Voli (TKJI)". aciaainsu.blogspot.co.id/2014/02/cara-mengukurkesegaran-jasmanikondisi.html?m=1, diakses 31 Oktober 2017.

Rahmani, Mikanda. 2014. Buku Super Lengkap Olahraga. Jakarta Timur : Dunia Cerdas.

Sutanto, Teguh. 2016. Buku Pintar Olahraga. Bantul : Perpustakaan Baru Press. Syafruddin, 1999. Dasar-Dasar Kepelatihan Olahraga. Padang : FIK UNP. Syafruddin, 2011. IImu Kepelatihan Olahraga. Padang : UNP Press.

Tabrani, Primadi. 2002. Hoki, Kreativitas Dan Riset Dalam Olahraga. Bandung : ITB

Taverner, Mitchell Claire. 2004. "Field Hockey Techniques \& Tactics". Australia. Wikihow. 2017. "How to Flick in Field Hockey". https://m.wikihow.com/flick-infield-hockey, diakses 31 Oktober 2017. 
www.best-fieldhockeysticks.com/best-field-hockey-stick-fo,r-defenders/, diakses 30 Oktober 2017.

www.picophotos.com/californiacup.html, diakses 31 Oktober 2017 